\title{
Lorazepam-induced reduction in activity mirrors decrements in cognitive and psychomotor performance
}

\author{
Jean Dawson ${ }^{1}$, Julia Boyle ${ }^{1}$, Neil Stanley ${ }^{1}$, Sig Johnsen ${ }^{1}$, Ian \\ Hindmarch ${ }^{1}$, Debra J. Skene ${ }^{2}$ \\ ${ }^{1}$ HPRU Medical Research Centre, School of Biomedical \& Molecular Sciences, University of \\ Surrey, Guildford, UK. \\ ${ }^{2}$ School of Biomedical \& Molecular Sciences, University of Surrey, Guildford, UK
}

\author{
Author for Correspondence: \\ Jean Dawson \\ HPRU Medical Research Centre, \\ School of Biomedical and Molecular Sciences, \\ University of Surrey, \\ GUILDFORD, \\ GU2 7XP \\ UK \\ Tel: + 441483689787 \\ Fax: + 441483689780 \\ e-mail: j.dawson@surrey.ac.uk
}


What this paper adds

What is already known -

The evaluation of psychotropic drug effects has been conducted utilising psychometric test batteries to assess changes in daytime cognition and psychomotor functioning and PSG to assess changes in sleep. Actigraphy is widely accepted as a non-invasive tool for assessing sleep-wake patterns in different groups. However, there is limited data to show that actigraphy can reliably measure the daytime and night-time characteristics of a CNS drug.

What this study adds -

This study provides further evidence that actigraphy is sensitive not only to the sedating effects of a hypnotic drug but also to the hangover effects of the drug the following morning. It confirms that the actiwatch is able to detect the effects of a hypnotic on actigraphically measured sleep. Further evidence that actigraphy can provide a reliable and sensitive indication of the time course of action of psychoactive drugs. 


\section{ABSTRACT}

Aim: To assess whether actigraphy is sensitive to lorazepam-induced changes in cognitive and psychomotor performance by measuring activity levels following placebo and lorazepam (LZP) dosing.

Methods: Healthy volunteers were randomised to a double-blind, placebocontrolled, crossover trial. Activity was recorded by actigraphy throughout each test period and pooled into $30 \mathrm{~min}$ bins for analysis. Following LZP dosing (2.5 mg at $18.00 \mathrm{~h})$ psychomotor and cognitive tests were conducted at regular intervals.

Results: Activity levels were significantly reduced between the psychometric tests $(P<0.02)$ at 2,3 and $5 \mathrm{~h}$ post dose and during the psychometric tests $(P$ $<0.02)$ at 2.5 and $4.5 \mathrm{~h}$ post dose. Subjects only felt sedated $(P<0.01)$ at 4.5 h post dose. Activity levels were also significantly reduced $(P<0.05)$ during sleep (23:00-07:00 h), and the following morning, activity levels remaining suppressed $(P<0.02)$ at 13.5 and $14 \mathrm{~h}$ post dose. Cognitive and psychomotor performance reflected changes in activity levels with significant impairment $(P<0.05)$ at $2.5,3.5,4.5$ and $14.5 \mathrm{~h}$ post dose.

Conclusion: This study showed that actigraphic activity levels were significantly reduced following LZP dosing. These changes were mirrored by impairment of cognitive and psychomotor performance. Actigraphy is therefore sensitive to the sedating effect of LZP and appears able to detect changes in sleep behaviour (hypnotic efficacy) and residual effects the following morning. Actigraphy may thus be a useful tool in assessing the psychopharmacology of CNS medication. 
Key words: Actigraphy; Hypnotics; Cognitive Performance; Psychomotor Performance; Hangover; Residual effect; 
Introduction

The development of actigraphy has allowed rest-activity patterns to be measured in difficult population groups. Whilst polysomnography (PSG) remains the gold standard for assessing sleep, actigraphy has offered a cheaper, less invasive alternative, which has the added advantage of being able to monitor rest and activity patterns for longer periods of time in situations where an intensive in-house assessment would be difficult.

Actigraphy is widely accepted as a non-invasive tool for assessing sleep-wake patterns in different groups [1-3], including insomnia [4,5], sleep-related breathing [6], children [7], restless legs [8], depression [9, 10] and circadian rhythm disorders [11]. There is limited data, however, to show that actigraphy can reliably measure the daytime and night-time characteristics of a CNS drug. Whether actigraph technology is sensitive to the sedating effects of medication and how accurately actigraphy is able to track drug pharmacokinetics and pharmacodynamics remains to be determined.

Currently the evaluation of psychotropic drug effects has been conducted utilising psychometric test batteries to assess daytime cognition and psychomotor functioning [12-14] whilst night-time sleep has been evaluated with PSG to assess changes in sleep architecture. This design is possible in Phase I and II studies but the data are limited to a relatively small number of volunteers and may not be relevant to the general population and in particular to the patient groups intended to receive the medication. Although it is not economical or logistically possible to conduct comprehensive in-house 
assessments in Phase III studies, actigraphy may be of use in the assessment of drug-induced changes in night-time sleep and in daytime activity in large scale patient studies. Changes in daytime activity levels may reflect increased sedation - a common side effect of some centrally acting compounds. Psychometric assessments have shown that a number of cognitive functions are adversely affected by increased sedation including information processing, memory and attention [15-17].

Previous research has assessed the effect of drugs on actigraphic sleep and daytime behaviour in small scale studies including sedatives [18,19], antidepressants [13,20,21], hypnotics [22,23], antihistamines [24-26] and stimulants [27]. The classes of drugs which are prescribed for inducing sleep, reducing anxiety or reducing a histaminic response have well documented side effects including reduction in activity during wake [22,23] and impairment of mental ability and alertness in the acute phase following drug administration $[28,29]$. Drug-induced reduction in activity has been studied in 'spontaneous' activity [29] and there are some data to suggest that actigraphy is able to detect "hangover effects" [18,22,28,30-33]. These studies, however, have employed different actigraphs and not the Actiwatch® (Cambridge Neurotechnology Ltd., UK) which has been used in this present study. There are important differences between these devices and the algorithms they deploy which means that confirmatory studies using the actiwatch are required to assess the utility of 'actigraphy' as a tool in psychopharmacology.

LZP, a hypnotic benzodiazepine, is prescribed to alleviate anxiety and aid sleep. LZP is usually prescribed in small doses $(1 \mathrm{mg})$ during the day to 
reduce anxiety and is also given in a single dose at night $(2.5 \mathrm{mg})$ to initiate sleep. It is readily absorbed reaching a peak concentration approximately $2 \mathrm{~h}$ after dosing with an elimination half life of about $12 \mathrm{~h}$ [34]. A dose of $2.5 \mathrm{mg}$ LZP has been shown to increase total sleep time and change sleep architecture at night [35,36], induce subjective daytime sleepiness [37], and reduce anxiety symptoms [38]. Previous studies have also shown that it impairs daytime psychomotor performance and memory [39]. Studying a hypnotic known to produce performance impairment such as LZP provides a useful tool to assess changes in motor activity in association with changes in both cognitive and psychomotor performance.

The aim of the present study was thus to evaluate the effect of a single dose (2.5 mg) of LZP, compared with placebo, on actigraphically assessed motor activity in healthy volunteers. The ability of actigraphy to detect LZP-induced changes in both spontaneous and controlled activity was assessed. In addition, whether actigraphy could distinguish changes in the sleep profile and any hangover effect of the drug was also determined.

\section{Methods}

\section{Study Design}

Volunteers were randomised to a double-blind, placebo-controlled, crossover design study where each volunteer acted as their own control. The data presented here were taken from a larger clinical trial and for the purpose of this investigation only the results of the study treatments of placebo and LZP are presented. Volunteers received either LZP $(2.5 \mathrm{mg})$ or placebo on two consecutive days, in a Latin Square design so that each volunteer received 
each treatment. All treatments were supplied in identical capsules and each oral dose was taken at 18:00 h on Day 2 and Day 3 of each study period. Each of the study periods was separated by a six day washout.

\section{Subjects}

Twenty four healthy male and female Caucasian volunteers were recruited onto the study of which 21 subjects (10 males, 11 females) completed both the study treatments. The mean $( \pm S D)$ age of the 21 subjects was $27.2 \pm 5.4$ years and the mean height, weight and body mass index (BMI) of the subjects at screening were $1.70 \pm 0.10 \mathrm{~m}, 69.2 \pm 9.4 \mathrm{~kg}$ and $23.7 \pm 2.2 \mathrm{~kg} / \mathrm{m}^{2}$, respectively.

All participants were in good health without any clinical history of physical or mental illness as assessed by a physician. No subjects were taking any concomitant medication (except oral contraceptives) likely to interfere with the study measures. Following a medical history, subjects underwent a medical examination (including 12-lead electrocardiogram, urinalysis, haematology, biochemistry, alcohol breath test and drugs of abuse screen). Written informed consent was obtained from all volunteers together with the consent of their medical practitioner to participate in the trial. The study was approved by the Ethics Committee of the South West Surrey Health Authority.

Volunteers were instructed to avoid late-nights and adhere to their usual bedtime (minimum 6-8 h sleep) before each of the study periods. In order to ensure compliance they were required to wear actigraphs continuously from the screening visit to study completion (maximum 8 weeks). The use of 
alcohol, nicotine and products containing caffeine were prohibited for $24 \mathrm{~h}$ before and on study days.

\section{Study Procedure}

Volunteers attended the Unit on Day 1 where a breath alcohol reading was taken and a urine sample obtained for drugs of abuse screening. The actigraph was removed, downloaded, reattached and checked for sleep wake compliance. Volunteers were familiarised with the study procedures and trained on the standard battery of psychometric tests (as described below) at the start of the trial in order to minimize learning effects during the study [40].

The psychometric test battery was performed at 07:00 h on Day 2 of each study period in order to obtain pre-treatment baseline recordings. Treatment (placebo or LZP) was administered at 18:00 h. After dosing the standard battery of psychomotor and cognitive tests was conducted at 1, 2, 3, 4 and 14 h post dose. During the study periods food consumption was strictly controlled and mealtimes were regulated, breakfast was consumed at 09:00 h; lunch at 12:00 h; a snack at 16:00 h; and dinner at 20:00 h on Day 1 and at 17:45 h on Day 2 and Day 3.

Bedtime (subjects supine in the dark in a standardised controlled environment) was from 23:00-07:00 $\mathrm{h}$ and volunteers were prevented from napping during the day. Blood samples were taken hourly at 15 min past the hour from 18:00-22:00 h on Day 3 to assess the pharmacokinetic profile of the drug (data not shown). 
Actigraphy

Volunteers were required to wear Actiwatches AW4 (Cambridge Neurotechnology Ltd., UK) on their non-dominant wrist for the duration of each study period (4 days), to monitor rest and activity. Actigraphy records activity in counts per epoch so drug-induced changes in activity may be observed and measured. Actiwatches were also worn from the screening visit to the start of the study (up to 30 days) and during the washout period of at least 6 days between each study period to ensure volunteer compliance and maintenance of a regular bedtime.

Activity was automatically calculated using the Sleepwatch® software (version 1.8) and its validated sleep/wake algorithm was used to calculate the amount of sleep-like activity, by scoring each individual epoch as sleep or wake, as well as various associated sleep parameters. The Actiwatch was set at the manufacturer's default setting and activity was captured in 1 min epochs. The mean activity for each 30 min time interval was calculated from dosing at 18:00 $\mathrm{h}$ for $24 \mathrm{~h}$. Each $30 \mathrm{~min}$ period before the psychometric tests was classified as "spontaneous activity" and each 30 min period during which the tests were performed was classified as "controlled activity". Data were captured electronically.

\section{Cognitive and Psychomotor Function}

Cognitive and psychomotor performance was measured in a 30 min test battery, which included Choice Reaction Time - HICKS (H-CRT); Continuous Tracking Task (CTT) and Line Analogue Rating Scales (LARS). These tests 
are known to be sensitive to the impairing effects of psychotropic compounds $[12,36]$.

\section{Choice Reaction Time - HICKS (HCRT)}

The Hick's CRT task is a measure of sensorimotor performance $[41,42]$. Volunteers were required to extinguish 1 of 6 equidistant red lights, illuminated at random, by touching the associated response button. The mean total reaction time (TRT) was measured as the sum of the recognition reaction time (RRT), the cognitive component, and the motor reaction time (MRT), the psychomotor component. All data were captured electronically.

\section{Continuous Tracking Task (CTT)}

This test is a divided attention interactive task of psychomotor performance [43-45]. Volunteers were required to keep a cursor in alignment with a moving target on a computer screen using a mouse, whilst simultaneously responding to a peripheral stimulus. The response measure of the tracking component of the task was the mean deviation in pixels, with lower scores indicative of more accurate tracking (CTT-ER). The mean reaction time in milliseconds was taken as the response measure of the peripheral awareness task (PRT) component. All data were captured electronically.

\section{Subjective Evaluation}

The Line Analogue Rating Scale (LARS) $[14,46]$ was employed as a measure of the subjective effect of the medication. Volunteers were required to indicate their present feeling, where the mid-point on a $10 \mathrm{~cm}$ scale represented their normal state of mind before treatment began. LARS was performed on Day 2 
at $07: 00 \mathrm{~h} ; 17: 00 \mathrm{~h} ; 19: 00 \mathrm{~h} ; 20: 00 \mathrm{~h} ; 21: 00 \mathrm{~h}$ and 22:00 $\mathrm{h}$ and then on Day 3 at 08:00 h. The mean scores of ratings of the 'tiredness', 'drowsiness' and 'alertness' factors were taken as a measurement of perceived sedation.

\section{Statistical Analysis}

Two way ANOVA was performed on the activity and psychometric data with time post dose and treatment as factors using PROC MIXED of SAS (Version 8.2). Post hoc tests were used to determine which times post dose were significantly different between drug and placebo.

\section{Results}

Activity

There was a significant effect of treatment on 'spontaneous' activity at 2 $\left(F_{(1,1057)}=5.88, P<0.05\right), 3\left(F_{(1,1258)}=35.82, P<0.0001\right)$ and $5 \mathrm{~h}\left(F_{(1,1296)}=\right.$ 6.07, $P<0.05)$ after dose with LZP significantly reducing activity compared to placebo. In addition, LZP significantly reduced 'controlled' activity during the psychometric tests at $2.5\left(F_{(1,1229)}=15.16, P<0.01\right)$ and $4.5 \mathrm{~h}\left(F_{(1,1283)}=\right.$ 15.94, $P<0.0001)$ post dose. Due to missing data, where some subjects removed the actigraph, the denominator degrees of freedom in the quoted ' $F$ ' ratio varied from one analysis to another. The overall effect of drug on activity is shown in Figure 1a. There was also a significant effect of LZP on 'spontaneous' activity immediately following the $8 \mathrm{~h}$ sleep period which occurred at 5-13 h post dose. Compared to placebo, LZP produced a significant reduction in spontaneous activity in the hour after waking, at 13.5 $\left(F_{(1,1296)}=5.66, P<0.05\right)$ and $14.0 \mathrm{~h}\left(F_{(1,1287)}=8.19, P<0.01\right)$ post dose. In contrast there was no significant effect of LZP on controlled activity at $14.5 \mathrm{~h}$ post dose (Figure 1a). 
Following a second dose of LZP on Day 3, the drug produced a similar significant reduction in activity at $2\left(F_{(1,1016)}=12.64, P<0.01\right), 2.5\left(F_{(1,1171)}=\right.$ 24.48, $P<0.0001), 3\left(F_{(1,1200)}=37.16, P<0.0001\right), 4.5\left(F_{(1,1224)}=28.91, P<\right.$ $0.0001)$ and $5 \mathrm{~h}\left(F_{(1,1237)}=8.23, P<0.01\right)$ post dose (Figure $\left.1 \mathrm{~b}\right)$. LZP again produced a significant reduction in activity immediately following the $8 \mathrm{~h}$ sleep period at $14 \mathrm{~h}\left(F_{(1,1228)}=7.24, P<0.05\right)$ post dose compared to placebo.

\section{Figure 1}

Activity was also continuously monitored during the sleep periods (23:00 07:00 h). On night 2, LZP produced a significant reduction in activity at the beginning and at the end of the sleep period at $5.5\left(F_{(1,1296)}=5.12, P<0.05\right)$, $7.5\left(F_{(1,1296)}=4.18, P<0.05\right), 10.5\left(F_{(1,1296)}=4.17, P<0.05\right)$, and $12.5 \mathrm{~h}$ $\left(F_{(1,1296)}=5.70, P<0.05\right)$ post dose compared to placebo (Figure 2a). A similar effect of LZP was observed on activity levels during the sleep period on night 3 , a significant reduction in activity again being noted at $5.5\left(F_{(1,1237)}=\right.$ 11.31, $P<0.001), 7.5\left(F_{(1,1237)}=7.81, P<0.01\right), 9.5\left(F_{(1,1237)}=10.46, P<\right.$ $0.01), 10.5\left(F_{(1,1237)}=9.10, P<0.01\right), 12\left(F_{(1,1237)}=3.92, P<0.05\right), 12.5$ $\left(F_{(1,1237)}=7.20, P<0.01\right)$ and $13.0 \mathrm{~h}\left(F_{(1,1237)}=4.79, P<0.05\right)$ post dose compared to placebo (Figure $2 b$ ).

\section{Figure 2}

\section{'Sleep-like’ minutes}

Each individual epoch was scored as sleep or wake, and 'sleep-like activity' was pooled into $30 \mathrm{~min}$ bins. Although there was an increase in the number of sleep-like epochs overall during the $5 \mathrm{~h}$ period following LZP administration, 
this was not statistically significant (Figure 3). However, there was a significant increase in 'sleep-like' minutes during 'spontaneous' activity at $4 \mathrm{~h}$ post dose $\left(F_{(1,20)}=4.28, P=0.0517\right)$.

\section{Figure 3}

\section{Sleep parameters}

The effect of LZP on various actigraphically-derived sleep parameters is shown in Table 1. Compared to placebo, LZP produced a significant reduction in the number of wake bouts $\left(F_{(1,20)}=6.59, P<0.05\right)$, the number of immobile phases $\left(F_{(1,20)}=5.92, P<0.05\right)$, percentage time moving $\left(F_{(1,20)}=5.41, P<\right.$ $0.05)$, mean activity score $\left(F_{(1,20)}=5.20, P<0.05\right)$, actual wake time $\left(F_{(1,20)}=\right.$ 6.71, $P<0.05)$ and the fragmentation index $\left(F_{(1,20)}=5.10, P<0.05\right)$ on the first night after dosing. LZP significantly increased actual sleep percent $\left(F_{(1,20)}\right.$ $=7.22, P<0.05)$, percentage time immobile $\left(F_{(1,20)}=5.41, P<0.05\right)$, mean length immobility $\left(F_{(1,20)}=8.76, P<0.01\right)$ and mean sleep bout time $\left(F_{(1,20)}=\right.$ 8.13, $P<0.01)$.

Similarly on the second night after dosing LZP reduced activity shown as a significant reduction in the percentage time moving $\left(F_{(1,19)}=9.09, P<0.01\right)$, percentage time immobile $\left(F_{(1,19)}=9.09, P<0.01\right)$ and in the number of minutes moving $\left(F_{(1,19)}=8.4, P<0.01\right)$. LZP also significantly increased actual sleep percent $\left(F_{(1,19)}=6.58, P<0.05\right)$ and actual wake time $\left(F_{(1,19)}=\right.$ 6.21, $P<0.05)$ (Table 1).

\section{Table 1}

The subjective evaluation of sedation was measured with LARS by combining the scores for 'tired', 'drowsy' and 'alert'. LZP caused a significant increase in subjective reports of sedation at $4.5 \mathrm{~h}$ post dose only $\left(F_{(1,20)}=10.72, P<0.01\right)$ 
(Figure 4a). The objective assessment of sedation was measured with the psychometric tests. Analysis of the total reaction time (TRT) component of the CRT task revealed that LZP also caused a significant increase in TRT at 2.5 $\left(F_{(1,21)}=9.07, P<0.01\right), 3.5\left(F_{(1,20)}=6.51, P<0.05\right), 4.5\left(F_{(1,20)}=9.75, P<\right.$ $0.01)$ and $14.5 \mathrm{~h}\left(F_{(1,20)}=12.61, P<0.01\right)$ post dose compared to placebo (Figure 4b). LZP also caused a significant increase in response time to the peripheral stimulus component of the CTT at $2.5\left(F_{(1,21)}=9.65, P<0.01\right), 3.5$ $\left(F_{(1,20)}=13.74, P<0.01\right), 4.5\left(F_{(1,20)}=10.14, P<0.01\right)$ and $14.5 \mathrm{~h}\left(F_{(1,20)}=\right.$ 5.09, $P<0.05)$ post dose compared to placebo (Figure $4 \mathrm{c}$ ). Analysis revealed that LZP also significantly affected tracking accuracy by increasing the error component $(\mathrm{CTT}-\mathrm{ERR})$ at $2.5\left(F_{(1,21)}=6.58, P<0.05\right), 3.5\left(F_{(1,20)}=6.84, P<\right.$ $0.05), 4.5\left(F_{(1,20)}=8.33, P<0.01\right)$, and $14.5 \mathrm{~h}\left(F_{(1,20)}=6.98, P<0.05\right)$ post dose compared to placebo (Figure 4d).

\section{Figure 4}

\section{Discussion}

It has been shown that reduced behavioural activity detected by actigraphy is reflected in both the psychometric and subjective assessment of sedation, psychomotor performance, general information processing skills and arousal $(20,21)$. The effects of LZP on the CNS and in particular the impairment of psychomotor function are well documented [39] so it provided a useful base on which to evaluate the ability of actigraphy to detect changes in activity patterns during the acute phase after a drug dose in relation to changes in psychomotor function. 
There is relatively little literature on the actigraphic profile of drugs. Whilst some authors $[22,24,29]$ have reported that the derived actigraph data show significant reductions in activity after dosing with various compounds, a variety of times blocks have been used ranging from 6 to $24 \mathrm{~h}$. Although this has provided an indication that actigraphy may be able to detect changes in behavioural activity due to the effects of medication, the use of these large analysis time frames may not be sufficient to provide a discrete profile of the drug and of its time course of effect on activity and pharmacodynamics. A study on the effects of several antihistamines in comparison to placebo [33], however, has provided evidence that by using the AMI 32 actigraph (Ambulatory Monitoring Inc., New York, USA) it is possible to show significant changes in actigraphically measured activity up to $6 \mathrm{~h}$ post dose with promethazine. This study collected data in short $10 \mathrm{sec}$ epochs and pooled the data into 20 min bins. A further study [33] on antidepressants in healthy volunteers recorded activity in epochs of $30 \mathrm{sec}$ and pooled the data into 12.5 min bins. This study demonstrated a reduction in activity levels following dothiepin dosing and showed that actigraphy closely followed the time course of psychometric impairment. However, due to the stimulating influence of the tests this effect was only significant in overall activity levels. Both of these previous studies were conducted in conjunction with psychometric tests and the results suggested that actigraphy is able to measure the sedative effects of drugs in relation to decrements in psychomotor function. The time bins used in these two studies, however, differed from the current study whereby data was collected in 1 min epochs, being the default setting of the device, and pooled into 30 min bins. This was in order to differentiate between 'controlled' activity during the 30 min test points and 'spontaneous' activity 
between the test points. The reduction in 'spontaneous' activity levels during the $5 \mathrm{~h}$ period after LZP dosing closely followed the impairment observed in the psychometric tests confirming that actigraphy is able to detect a druginduced effect.

Data need not only be calculated in activity counts, reduced daytime activity can also be interpreted as sleepiness or 'sleep-like' behaviour by using the propriety sleep analysis software algorithm to score each epoch as either sleep or wake. Various studies $[24,28,29]$ have successfully used this method to calculate overall 'sleep-like' behaviour. As in the present study, no significant effect of treatment was found on the overall number of 'sleep-like' epochs during the $5 \mathrm{~h}$ period post dose, however, significance was found in the 30 min interval at $4 \mathrm{~h}$ post dose. This was during the half hour just prior to the $4.5 \mathrm{~h}$ test point which also showed the greatest impairment in the performance of the psychometric tests and the subjective rating of sedation in the LARS.

LZP has been shown to alter sleep architecture as determined by PSG [35], by reducing sleep latency, number of awakenings, \% Stage 1 sleep and REM, whilst increasing total sleep time and Stage 2 sleep. In the present study the actigraphic analysis of the sleep period revealed significant reductions in the activity levels at the beginning and end of the sleep period indicating more restful sleep which is consistent with the previous findings. The actigraphic sleep parameters confirm this improvement in sleep showing an increase in the actual sleep percent and the length of the sleep bouts, a reduction in the number of wake bouts and the fragmentation index. This clearly indicates that 
the actigraphy data are consistent with previous PSG findings of the effect of LZP and provides a less expensive non-invasive alternative for detecting changes in sleep due to the effect of a drug.

As psychoactive drugs have varied durations of efficacy, it is important to establish the maximum duration of impairment in order to provide safety data when prescribing. If a hypnotic taken to aid sleep has residual or hangover effects in the morning clearly this may be a safety hazard. Previous studies $[18,19,22]$ have shown that actigraphy is useful in providing data on residual effects, by showing a reduction in activity levels following dosing. However, these data $[18,19,22]$ were presented in large time blocks of $4 \mathrm{~h}$ or more. The present study shows that actigraphy is able to detect a significant reduction in activity in the waking hour immediately following the sleep period. This was confirmed by the psychomotor impairment observed in the morning following LZP compared to placebo. Although the LARS did not show that subjects taking LZP were more sedated in the morning, the results of the psychometric tests revealed that LZP had caused a sedating effect and impaired their cognitive ability.

Similar results were obtained following a repeated dose of LZP. There was a significant reduction in activity in the $5 \mathrm{~h}$ period immediately following dosing, as well as a hangover effect the following morning. The actigraphic sleep showed a similar profile with the second dose of LZP again improving sleep, by reducing movement. This finding is in agreement with a previous study using repeated dosing [22]. 
In conclusion, this study provides further evidence that actigraphy is sensitive not only to the sedating effects of a hypnotic drug as measured by a reduction in behavioural activity but also to the hangover effects of the drug the following morning. It also confirms that the actiwatch is able to detect the effects of a hypnotic on actigraphically measured sleep. Moreover this study, following the recommendation of Roehrs and colleagues [24], adds further evidence that actigraphy can provide a reliable and sensitive indication of the time course of action of psychoactive drugs. Studies using actigraphy to measure the effects of other psychoactive compounds and drug groups in both subject and patient populations both in the laboratory and in field studies will be necessary to further validate this method as a useful tool in psychopharmacology. 


\section{References}

1. Ancoli-Israel S, Cole R, Alessi C, Chambers M, Moorcroft W, Pollak CP. The role of actigraphy in the study of sleep and circadian rhythms. Sleep 2003; 26: 342-92.

2. Sadeh A, Hauri PJ, Kripke DF, Lavie P. The role of actigraphy in the evaluation of sleep disorders. Sleep 1995; 18: 288-302.

3. Littner M, Kushida CA, Anderson WM, Bailey D, Berry RB, Davila DG, Hirshkowitz M, Kapen S, Kramer M, Loube D, Wise M, Johnson SF; Standards of Practice Committee of the American Academy of Sleep Medicine. Practice parameters for the role of actigraphy in the study of sleep and circadian rhythms: an update for 2002. Sleep 2003; 26:337-41.

4. Lichstein KL, Stone KC, Donaldson J, Nau SD, Soeffing JP, Murray D, Lester KW, Aguillard RN. Actigraphy validation with insomnia. Sleep 2006; 29: 232-9.

5. Hauri PJ, Wisbey J. Wrist actigraphy in insomnia. Sleep 1992; 15: 293-301.

6. Acebo C, LeBourgeois MK. Actigraphy. Respir Care Clin N Am 2006; 12: 23-30.

7. Acebo C, Sadeh A, Seifer R, Tzischinsky O, Hafer A, Carskadon MA. Sleep/wake patterns derived from activity monitoring and maternal report for healthy 1 - to 5-year-old children. Sleep 2005; 28:1568-77.

8. King MA, Jaffre MO, Morrish E, Shneerson JM, Smith IE. The validation of a new actigraphy system for the measurement of periodic leg movements in sleep. Sleep Med 2005; 6: 507-13.

9. Royant-Parola S, Borbely AA, Tobler I, Benoit O, Widlocher D. Monitoring of long-term motor activity in depressed patients. Br J Psychiatry 1986; 149: 288-93.

10. Raoux N, Benoit O, Dantchev N, Denise P, Franc B, Allilaire JF, Widlocher D. Circadian pattern of motor activity in major depressed patients undergoing antidepressant therapy: relationship between actigraphic measures and clinical course. Psychiatry Res 1994; 52 : 85-98.

11. Lockley SW, Skene DJ, Arendt J. Comparison between subjective and actigraphic measurement of sleep and sleep rhythms. J. Sleep Res 1999; 8: 175-183. 
12. Hindmarch I, Trick L, Ridout F. A double-blind, placebo- and positive-internal-controlled (alprazolam) investigation of the cognitive and psychomotor profile of pregabalin in healthy volunteers. Psychopharmacology (Berl) 2005; 183: 133-43.

13. Fairweather DB, Ashford J, Hindmarch I. Effects of fluvoxamine and dothiepin on psychomotor abilities in healthy volunteers. Pharmacol Biochem Behav 1996; 53: 265-9.

14. Hindmarch I. Psychomotor function and psychoactive drugs. Br J Clin Pharmacol 1980; 10: 189-209.

15. Patat A, Klein MJ, Hucher M. Effects of single oral doses of clobazam, diazepam and lorazepam on performance tasks and memory. Eur J Clin Pharmacol 1987; 32: 461-6.

16. Soo-ampon S, Wongwitdecha N, Plasen S, Hindmarch I, Boyle J. Effects of word frequency on recall memory following lorazepam, alcohol, and lorazepam alcohol interaction in healthy volunteers. Psychopharmacology (Berl) 2004; 176: 420-5.

17. Hindmarch I, Patat A, Stanley N, Paty I, Rigney U. Residual effects of zaleplon and zolpidem following middle of the night administration five hours to one hour before awakening. Hum Psychopharmacol 2001; 16:159-167.

18. Borbely AA, Youmbi-Balderer G, Jaggi-Schwarz K. Zolpidem (10 mg and $20 \mathrm{mg}$ ): Hypnotic action and residual effects after a single bedtime dose. In: Imidazopyridines in Sleep Disorders, eds Sauvenet JP, Langer SZ, Morselli PL, New York: Raven Press, 1988: 205-210.

19. Mattmann P, Loepfe M, Scheitlin T, Schmidlin D, Gerne M, Strauch I, Lehmann D, Borbely AA. Day-time residual effects and motor activity after three benzodiazepine hypnotics. Arzneimittelforschung 1982; 32: 461-5.

20. Stanley N, Hindmarch I. Actigraphy can measure antidepressant-induced daytime sedation in healthy volunteers. Hum Psychopharmacol 1997; 12: 437-443.

21. Stanley N, Fairweather DB, Hindmarch I. Effects of fluoxetine and dothiepin on 24-hour activity in depressed patients. Neuropsychobiology 1999; 39: 44-8. 
22. Takahashi T, Okajima Y, Otsubo T, Shinoda J, Mimura M, Nakagome K, Kamijima K. Comparison of hangover effects among triazolam, flunitrazepam and quazepam in healthy subjects: a preliminary report. Psychiatry Clin Neurosci 2003; 57: 303-9.

23. Borbely AA, Loepfe M, Mattmann P, Tobler I. Midazolam and triazolam: hypnotic action and residual effects after a single bedtime dose Arzneimittelforschung 1983; 33: 1500-2.

24. Roehrs T, Turner L, Roth T. Effects of sleep loss on waking actigraphy. Sleep 2000; 15: 23: 793-7.

25. Hindmarch I, Shamsi Z, Stanley N, Fairweather DB. A double-blind, placebo-controlled investigation of the effects of fexofenadine, loratadine and promethazine on cognitive and psychomotor function. Br J Clin Pharmacol 1999; 48: 200-6.

26. Shamsi Z, Kimber S, Hindmarch I. An investigation into the effects of cetirizine on cognitive function and psychomotor performance in healthy volunteers. Eur $\mathrm{J}$ Clin Pharmacol 2001; 56: 865-71.

27. Hindmarch I, Rigney U, Stanley N, Quinlan P, Rycroft J, Lane J. A naturalistic investigation of the effects of day-long consumption of tea, coffee and water on alertness, sleep onset and sleep quality. Psychopharmacology (Berl) 2000; 149: 203-16.

28. Kawahara R, Nishimura S, Inagaki Y, Taenaka N, Kawahara H. Actigraphic assessment of the preoperative hypnotic effects of brotizolam and zopiclone. Acta Anaesthesiol Belg 2002; 53: 27-31.

29. Kiang M, Daskalakis ZJ, Christensen BK, Remington G, Kapur S. Actigraphic measurement of the effects of single-dose haloperidol and olanzapine on spontaneous motor activity in normal subjects. J Psychiatry Neurosci 2003; 28: 293-9.

30. Borbely AA. Ambulatory motor activity monitoring to study the timecourse of hypnotic action. Br J Clin Pharmacol 1984; 18: 83S-86S.

31. O'Neill WM, Hanks GW, Simpson P, Fallon MT, Jenkins E, Wesnes K. The cognitive and psychomotor effects of morphine in healthy subjects: a randomized controlled trial of repeated (four) oral doses of dextropropoxyphene, morphine, lorazepam and placebo. Pain 2000; 85: 209-15. 
32. Klosch G, Gruber G, Anderer P, Saletu B. Activity monitoring in sleep research, medicine and psychopharmacology. Wien Klin Wochenschr 2001; 113: 288-95.

33. Stanley N. Actigraphy in psychopharmacology. In: Human Psychopharmacology Measures and Methods. Eds Hindmarch I, Stonier PD, Chichester: John Wiley \& Sons 1997: 6: 67-93.

34. Kyriakopoulos AA, Greenblatt DJ, Shader RI. Clinical pharmacokinetics of lorazepam: a review. J Clin Psychiatry 1978; 39: 16-23.

35. Grozinger M, Kogel P, Roschke J. Effects of lorazepam on the automatic online evaluation of sleep EEG data in healthy volunteers. Pharmacopsychiatry 1998; 31: 55-9.

36. Roschke J, Kogel P, Grozinger M. Lorazepam and the sleep EEG's microstructure: A novel approach to quantitative pharmaco-EEG investigations. German Journal of Psychiatry 2000; 3: 13-18.

37. van Laar M, Volkerts E, Verbaten M. Subchronic effects of the GABA-agonist lorazepam and the $5-\mathrm{HT} 2 \mathrm{~A} / 2 \mathrm{C}$ antagonist ritanserin on driving performance, slow wave sleep and daytime sleepiness in healthy volunteers. Psychopharmacology (Berl) 2001; 154: 189-97.

38. Laakmann G, Schule C, Lorkowski G, Baghai T, Kuhn K, Ehrentraut S. Buspirone and lorazepam in the treatment of generalized anxiety disorder in outpatients. Psychopharmacology (Berl). 1998; 136: 357-66.

39. Baselt R. (editor) Lorazepam. In: Drug Effects on Psychomotor Performance. Foster City: Biomedical Publications, 2001: 215-220.

40. Parkin C, Kerr JS, Hindmarch I. The effects of practice on choice reaction time and critical flicker fusion threshold. Hum Psychopharmacol 1999; 12: 65-70.

41. Hindmarch I, Tiplady B. A comparison of the psychometric effects of remoxipride with those of haloperidol, thioridazine and lorazepam in healthy volunteers. Hum Psychopharmacol 1994; 9: 43-49.

42. Sherwood N, Kerr JS. The reliability, validity and pharmacosensitivity of four psychomotor tests. In: Human Psychopharmacology Measures and Methods. Eds Hindmarch I, Stonier PD, Chichester: John Wiley \& Sons 1993: 4: 1-14. 
43. Hindmarch I. Three antidepressants (amytriptyline, dothiepin, fluoxitine), with and without alcohol, compared to placebo on tests of psychomotor ability related to car driving. Hum Psychopharmacol 1987; 2: 177-183.

44. Kerr JS, Powell J, Hindmarch I. The effects of reboxetine and amitriptyline, with and without alcohol on cognitive function and psychomotor performance. $\mathrm{Br} \mathrm{J}$ Clin Pharmacol 1996; 42: 239-41.

45. Parkin C, Fairweather DB, Shamsi Z, Stanley N, Hindmarch I. The effects of cigarette smoking on overnight performance. Psychopharmacology (Berl) 1998; 136: 172-8.

46. Hindmarch I, Gudgeon AC. The effects of clobazam and lorazepam on aspects of psychomotor performance and car handling ability. Br J Clin Pharmacol 1980; 10: 145-50. 
Table 1 Effect of LZP and placebo on actigraphic sleep parameters

\begin{tabular}{|c|c|c|c|c|}
\hline \multirow[b]{2}{*}{ Variable } & \multicolumn{2}{|c|}{ Night 1} & \multicolumn{2}{|c|}{ Night 2} \\
\hline & Placebo & Lorazepam & Placebo & Lorazepam \\
\hline Actual Sleep Percent & $88 \pm 1$ & $91 \pm 1$ * & $89 \pm 1$ & $92 \pm 1$ * \\
\hline Actual Wake Time (mins) & $56 \pm 5$ & $45 \pm 5$ * & $53 \pm 7$ & $40 \pm 7^{*}$ \\
\hline Number of Wake Bouts & $28 \pm 2$ & $22 \pm 2$ * & $27 \pm 2$ & $22 \pm 2$ \\
\hline Number of Immobile Phases & $41 \pm 2$ & $34 \pm 2$ * & $40 \pm 2$ & $35 \pm 2$ \\
\hline Percentage Time Immobile & $88 \pm 1$ & $90 \pm 1$ * & $87 \pm 1$ & $90 \pm 1^{* *}$ \\
\hline Percentage Time Moving & $12 \pm 1$ & $10 \pm 1$ * & $13 \pm 1$ & $10 \pm 1^{\star *}$ \\
\hline Mean Activity Score & $14 \pm 2$ & $11 \pm 2$ * & $13 \pm 2$ & $9 \pm 1$ \\
\hline Fragmentation Index & $26 \pm 2$ & $21 \pm 2$ * & $25 \pm 3$ & $21 \pm 2$ \\
\hline Number of Minutes Moving & $57 \pm 5$ & $47 \pm 4$ * & $61 \pm 5$ & $47 \pm 3^{* *}$ \\
\hline Total Activity Score & $6574 \pm 720$ & $5132 \pm 777$ * & $6281 \pm 1058$ & $4404 \pm 419$ \\
\hline Sleep Efficiency Percentage & $86 \pm 1$ & $90 \pm 1$ & $87 \pm 2$ & $91 \pm 1$ \\
\hline Number of $1 \mathrm{~min}$ Immobile Minutes & $6 \pm 5$ & $4 \pm 4$ & $5 \pm 1$ & $4 \pm 1$ \\
\hline Mean Length Immobility (mins) & $11 \pm 1$ & $14 \pm 1$ ** & $11 \pm 1$ & $13 \pm 1$ \\
\hline Number of Immobile Minutes & $413 \pm 5$ & $429 \pm 4$ & $411 \pm 6$ & $430 \pm 3$ \\
\hline Percentage of $1 \mathrm{~min}$ Immobile Minutes & $14 \pm 2$ & $11 \pm 1$ & $12 \pm 2$ & $12 \pm 2$ \\
\hline Mean Sleep Bout Time (mins) & $17 \pm 1$ & $23 \pm 2$ ** & $18 \pm 2$ & $24 \pm 2$ \\
\hline Mean Wake Bout Time (mins) & $2 \pm 0.1$ & $2 \pm 0.1$ & $2 \pm 0.2$ & $2 \pm 0.1$ \\
\hline Mean Activity Score in Active Periods & $111 \pm 7$ & $104 \pm 10$ & $96 \pm 7$ & $93 \pm 7$ \\
\hline Wake Movement Average & $186 \pm 13$ & $183 \pm 12$ & $167 \pm 12$ & $156 \pm 10$ \\
\hline Sleep Latency (mins) & $9 \pm 2$ & $4 \pm 1$ & $8 \pm 2$ & $3 \pm 1$ \\
\hline \multicolumn{5}{|c|}{$\begin{array}{l}\text { Data are provided as sleep parameters calculated with the Sleepwatch Algorithm and } \\
\text { presented as mean } \pm \text { SEM }(n=21) \\
{ }^{\star} P<0.05,{ }^{* *} P<0.01 \text { versus corresponding placebo }\end{array}$} \\
\hline
\end{tabular}




\section{Figure legends}

Figure 1

Time course of effect of placebo ( $\square)$ and LZP $2.5 \mathrm{mg}(\square)$ on activity as measured by actigraphy (\# = psychometric test point, controlled activity) on (a) Day 2 and (b) Day 3.

${ }^{\star} P<0.05,{ }^{* *} P<0.01,{ }^{* *} P<0.0001$ compared to corresponding placebo

Data are presented as mean \pm SEM $(n=21)$

Figure 2

Time course of effect of placebo ( $\square)$ and LZP $2.5 \mathrm{mg}(\square)$ on activity during sleep on (a) Night 2 and (b) Night 3 as measured by actigraphy, $5 \mathrm{~h}$ post dose corresponds to $23: 00 \mathrm{~h}$.

${ }^{\star} P<0.05,{ }^{* \star} P<0.01$ compared to corresponding placebo

Data are presented as mean \pm SEM $(n=21)$

Figure 3

Time course of effect of placebo (ם) and LZP $2.5 \mathrm{mg}(\square)$ on 'sleep-like' minutes on Day 2 during 'spontaneous' activity.

${ }^{*} P=0.0517$ compared to corresponding placebo

Data are presented as mean \pm SEM $(n=21)$

Figure 4

Time course of effect of placebo ( $\square)$ and LZP $2.5 \mathrm{mg}(\square)$ on (a) sedation component of LARS, (b) total reaction time of CRT (c) reaction time of CTT and (d) tracking error of CTT.

${ }^{*} P<0.05,{ }^{*} P<0.01$ compared to corresponding placebo

Data are presented as mean \pm SEM $(n=21)$ 
Figure 1
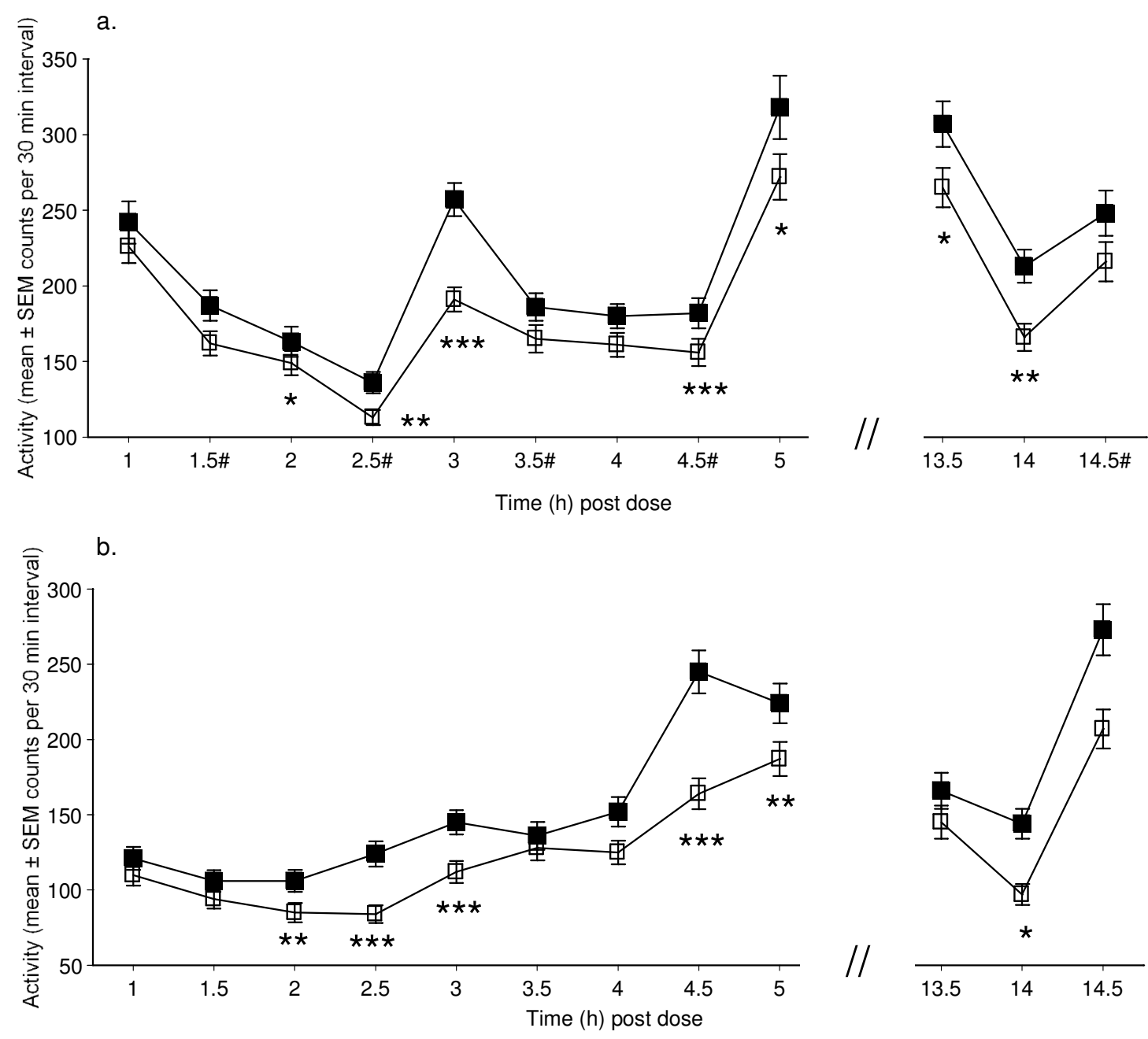


\section{Figure 2}

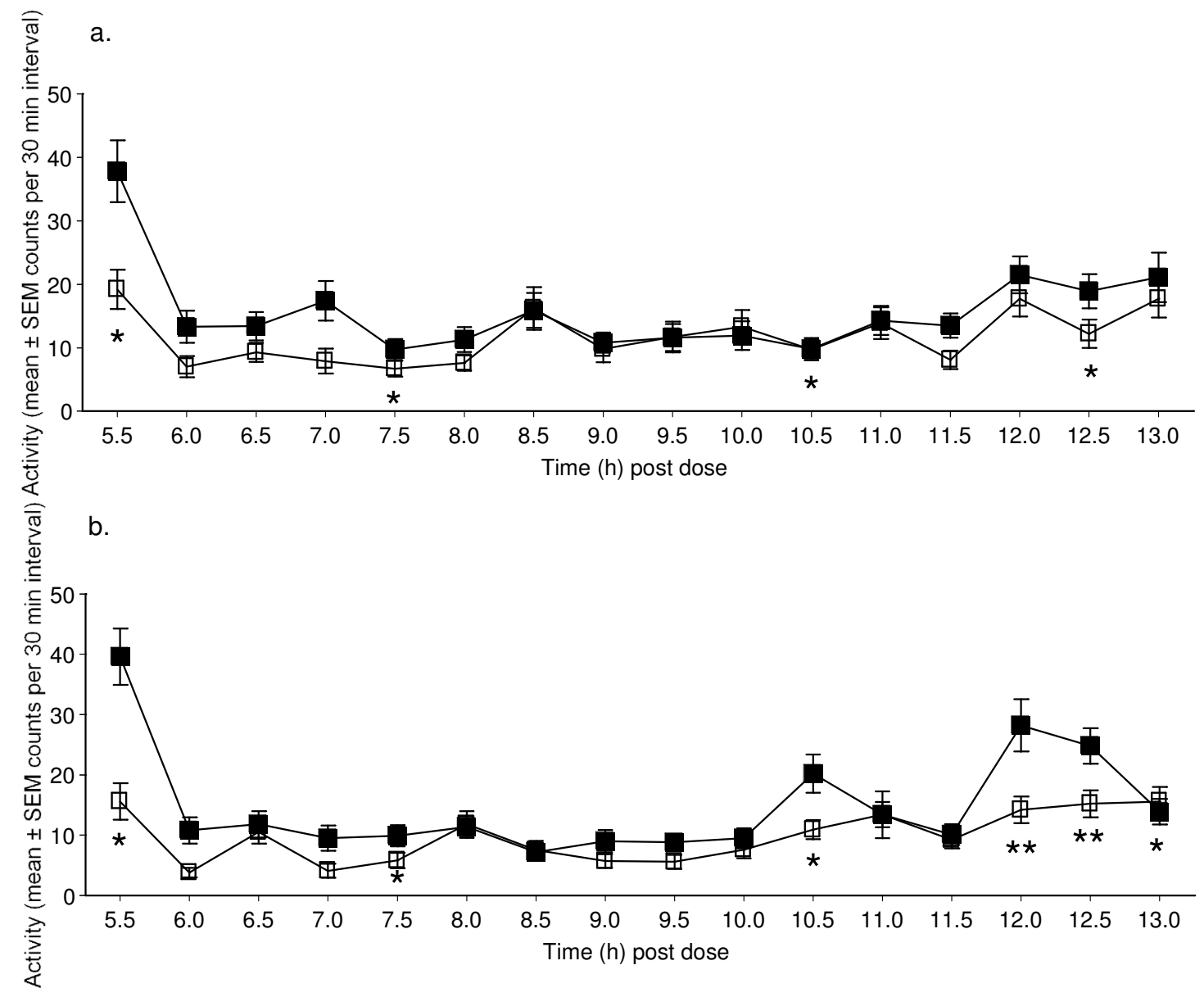


Figure 3

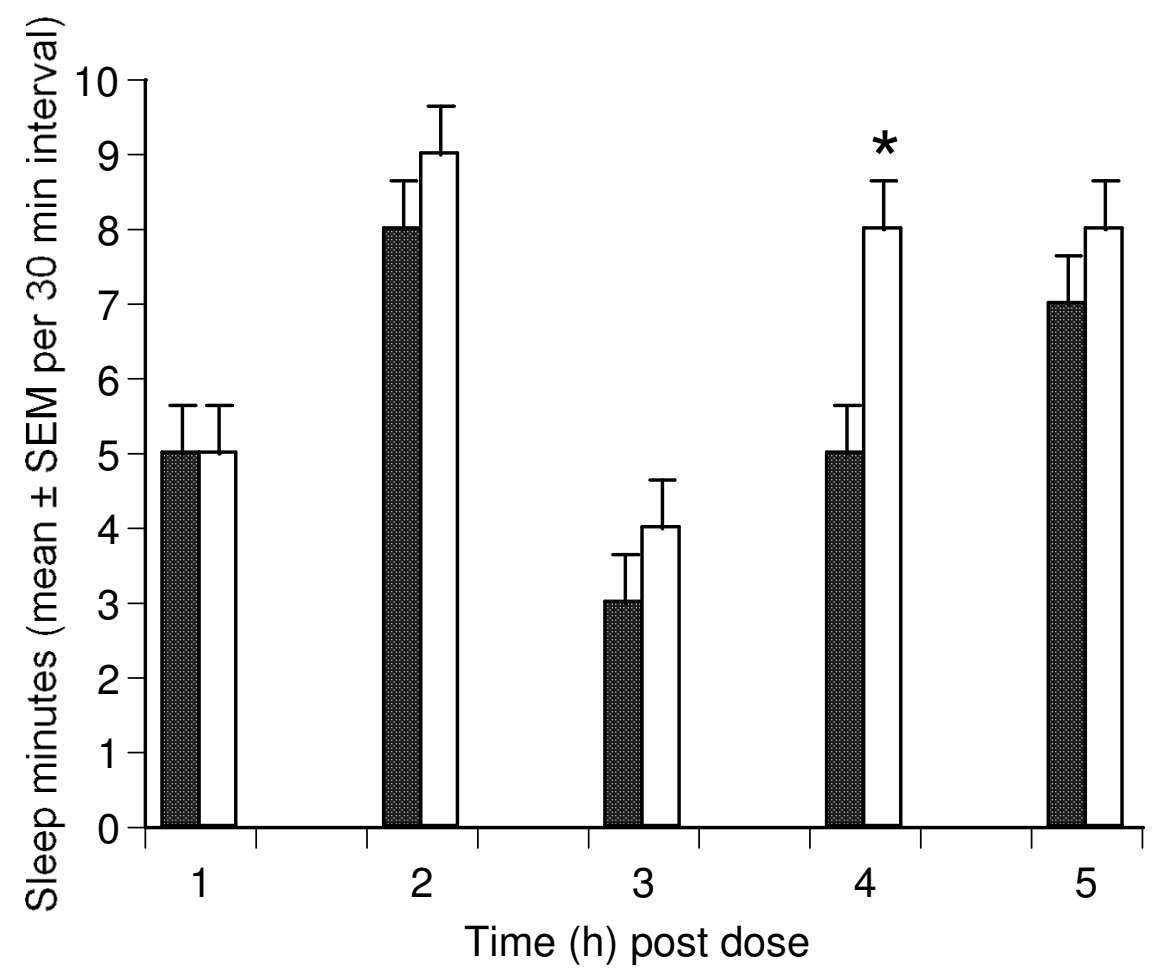


Figure 4
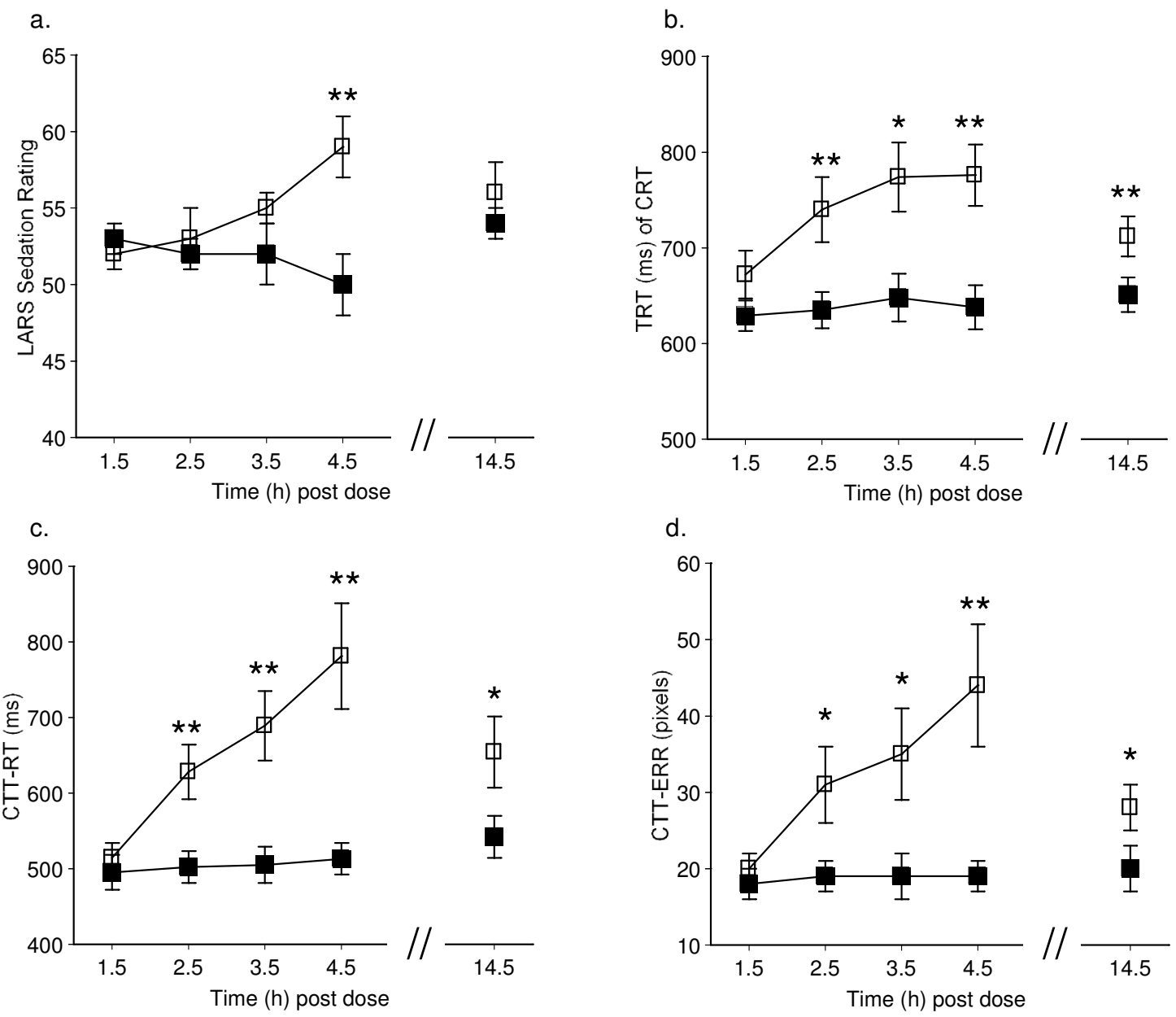